\title{
Efeito de diferentes temperaturas na qualidade de mandioquinha-salsa minimamente processada
}

\author{
Elisângela Elena Nunes ${ }^{1}$; Eduardo Valério de B Vilas Boas²; Roberta H Piccoli²; Andréa Luiza RP Xisto²; \\ Brígida M Vilas Boas ${ }^{3}$ \\ ${ }^{1}$ UFT, C. Postal 66, 77402-970 Gurupi-TO; ${ }^{2}$ UFLA, Dep ${ }^{\text {to }}$ Ciência dos Alimentos, C. Postal 3037, 37200-000 Lavras-MG; ${ }^{3}$ Instituto \\ Federal de Educação, Ciência e Tecnologia Sul de Minas, Rod. Machado-Paraguaçu, km 3, Santo Antônio, 37750-000 Machado-MG; \\ evbvboas@dca.ufla.br; rhpiccoli@dca.ufla.br; andreaxisto@hotmail.com; elisanunescarvalho@hotmail.com; bmvboas@hotmail.com
}

\section{RESUMO}

O objetivo do presente trabalho foi avaliar a vida útil de mandioquinha-salsa 'Amarela de Senador Amaral' minimamente processada e armazenada em três temperaturas de armazenamento. As raízes foram descascadas manualmente, fatiadas $( \pm 1 \mathrm{~cm}$ de espessura), imersas em solução de dicloro isocianurato de sódio 100 mg L $\mathrm{L}^{-1}$ por 15 minutos e acondicionadas em embalagem rígida de polipropileno ( $15 \times 11,5 \times 4,5 \mathrm{~cm})$. As embalagens, contendo cerca de $150 \mathrm{~g}$ de raízes minimamente processadas, foram armazenadas a $0 \pm 1^{\circ} \mathrm{C}, 5 \pm 1^{\circ} \mathrm{C}$ ou $10 \pm 1^{\circ} \mathrm{C}$ durante 15 dias, sendo realizadas análises a cada 3 dias. $\mathrm{O}$ delineamento experimental foi inteiramente casualizado em fatorial $3 \times 6$, sendo 3 temperaturas de armazenamento e 6 períodos de armazenamento, com 3 repetições. $\mathrm{O}$ armazenamento a $0^{\circ} \mathrm{C}$ determinou, ao longo do armazenamento, aumento nos valores de $\mathrm{L}^{*} \mathrm{e} \mathrm{b}^{*}$, menores valores de $\mathrm{a}^{*}$, menor atividade da peroxidase, polifenoloxidase, poligalacturonase, solubilização péctica e taxa respiratória, sendo a temperatura mais indicada para o armazenamento da mandioquinha-salsa 'Amarela de Senador Amaral' minimamente processada.

Palavras-chave: Arracacia xanthorrhiza, processamento mínimo, peroxidase, polifenoloxidase.

\begin{abstract}
Effect of different temperatures on the quality of fresh-cut Peruvian carrot

The shelf life of fresh-cut Peruvian carrots 'Amarela de Senador Amaral', stored under three temperatures, was evaluated. The roots were peeled manually, sliced ( $\pm 1 \mathrm{~cm}$ thick), immersed in a solution of sodium dichloroisocyanurate $100 \mathrm{mg} \mathrm{L}^{-1}$ during 15 minutes and packed in rigid polypropylene package $(15 \times 11.5 \times 4.5 \mathrm{~cm})$. The packages containing around $150 \mathrm{~g}$ of fresh cut roots were stored under $0 \pm 1^{\circ} \mathrm{C}, 5 \pm 1^{\circ} \mathrm{C}$ or $10 \pm 1^{\circ} \mathrm{C}$ during 15 days. The analyses were performed every 3 days. The experimental design was completely randomized in a $3 \times 6$ factorial ( 3 storage temperature) and 6 periods of storage, with three replicates. The storage at $0^{\circ} \mathrm{C}$ provided higher $\mathrm{L}^{*}$ and $\mathrm{b}^{*}$ values, lower $\mathrm{a}^{*}$ values, lower peroxidase, polyphenoloxidase and polygalacturonase activity, pectic solubilization and respiration rate. This temperature is the most proper for the storage of the fresh-cut peruvian carrot 'Amarela de Senador Amaral'.
\end{abstract}

Keywords: Arracacia xanthorrhiza, fresh-cut, polyphenoloxidase, peroxidase.

(Recebido em 6 de maio de 2009; aceito em 16 de agosto de 2010)

(Received on May 6, 2009; accepted on August 16, 2010)

\begin{abstract}
$\mathrm{A}$ mandioquinha-salsa é uma planta eudicotiledônea, da ordem Umbellales, família Apiaceae (Umbelliferae), gênero Arracacia, espécie Arracacia xanthorrhiza Bancroft. A família das apiáceas compreende também a cenoura, a salsa, o coentro, o aipo e o funcho, entre outras.

De acordo com Pereira (1997), a mandioquinha-salsa caracteriza-se como alimento essencialmente energético, destacando-se os teores de carboidratos em relação aos demais nutrientes. Dos carboidratos totais, cerca de $80 \%$ correspondem ao amido e $6 \%$ aos açúcares totais. O amido de mandioquinha-salsa contém baixos teores de amilopectina e ausência total de fatores anti-nutricionais, conferindolhe alta digestibilidade. As proteínas são incompletas, como ocorre em outras
\end{abstract}

raízes e tubérculos, devido à deficiência na maioria dos aminoácidos essenciais. É notadamente fonte de vitaminas e minerais. Entre as vitaminas, ressaltam-se as do complexo B (tiamina, riboflavina, niacina e piridoxina) e a vitamina $\mathrm{A}$. Entre os minerais, destacam-se o cálcio, o magnésio, o fósforo e o ferro. Devido a esses fatores, é especialmente recomendada na alimentação de crianças e pessoas idosas.

Raízes embaladas e mantidas sob refrigeração são formas de apresentação para o mercado varejista que agregam valor ao produto e que também podem aumentar a sua vida de prateleira (Avelar Filho, 1989). Adicionalmente, agrega valor ao produto final, trazendo maior retorno financeiro para o produtor.

Recentemente, permissionários instalados na Ceagesp têm levado o produto in natura para mercados distantes, destacadamente para as principais capitais nordestinas. Isso foi possível graças ao embalamento a vácuo, transporte refrigerado em caixas de isopor e disposição do produto em gôndolas refrigeradas nos pontos de venda, em geral grandes redes de supermercados. O prazo de validade do produto é de 15 dias (Madeira \& Souza, 2004).

A mandioquinha-salsa é uma das hortaliças que apresenta grande demanda na forma minimamente processada. Entretanto, diversos cuidados devem ser tomados no processamento mínimo, relacionados à espessura do corte, controle do metabolismo e uso de refrigeração.

Os produtos minimamente processados devem ser mantidos em refrigeração, sendo este fator importante no retardamento da perda de qualidade, na 
alteração da composição da atmosfera modificada ao redor do produto, na perda das características nutricionais, na diminuição da contaminação microbiológica, na manutenção da qualidade sensorial dos mesmos, e também na minimização das injúrias provocadas pelo processamento (Brecht, 1995). Estes produtos geralmente são mais perecíveis que os que lhes deram origem e, por isso, devem ser mantidos a baixas temperaturas, sendo $0^{\circ} \mathrm{C}$ considerada ideal. Entretanto, por razões econômicas, são utilizadas temperaturas ao redor de 5 a $10^{\circ} \mathrm{C}$, acelerando assim o processo de deterioração (Rinaldi et al., 2005). Uma das técnicas mais eficientes para aumentar a durabilidade de hortaliças é o seu armazenamento sob baixa temperatura. A temperatura diminui a taxa de respiração, a perda de água e retarda o amadurecimento de vegetais (Lana et al., 1998).

O objetivo deste trabalho foi avaliar a vida útil pós-colheita de mandioquinhas-salsa minimamente processadas, sob três temperaturas de armazenamento, buscando adequar uma melhor temperatura de armazenamento.

\section{MATERIAL E MÉTODOS}

Raízes de mandioquinhas-salsa cultivar Amarela de Senador Amaral foram adquiridas no comércio local de Lavras e transportadas para o laboratório da Universidade Federal de Lavras. As raízes foram selecionadas, descartandose aquelas que apresentavam injúrias, lavadas em água corrente com detergente, sendo em seguida imersas em solução de dicloro isocianurato de sódio $100 \mathrm{mg}$ $\mathrm{L}^{-1}$ por 20 minutos, drenado o excesso de solução sanificante com auxílio de peneiras plásticas e secas ao ar.

As etapas do processamento constaram de: a) Corte: as raízes foram descascadas manualmente, fatiadas $(1 \mathrm{~cm}$ de espessura) com auxílio de multiprocessador MASTER AT; b) Sanificação: as fatias foram imersas em solução de dicloro isocianurato de sódio $100 \mathrm{mg}$ $\mathrm{L}^{-1}$ por 15 minutos; c) Eliminação do excesso de água: as fatias foram drenadas por aproximadamente 3 minutos em escorredor doméstico; d) Embalagem: após a retirada do excesso de água as fatias de mandioquinhas-salsa foram acondicionadas em embalagem rígida de polipropileno (15 x 11,5 x 4,5 cm); e e) Armazenamento: as embalagens, contendo cerca de 150 gramas de minimamente processadas, foram armazenadas em câmaras frias nas temperaturas de $0 \pm 1{ }^{\circ} \mathrm{C}, 5 \pm 1^{\circ} \mathrm{C}$ e $10 \pm 1^{\circ} \mathrm{C}$ por um período de 15 dias. Práticas de higiene foram utilizadas para desinfecção do ambiente, facas e utensílios, utilização de equipamentos de proteção individual pelos manipuladores.

O delineamento experimental foi inteiramente casualizado em fatorial $3 \times 6$, sendo 3 temperaturas de armazenamento $\left(0,5\right.$ e $\left.10^{\circ} \mathrm{C}\right)$ e 6 períodos de armazenamento $(0,3,6,9,12$ e 15 dias), com 3 repetições. Cada embalagem contendo $150 \mathrm{~g}$ de mandioquinha-salsa minimamente processada foi considerada como parcela experimental. As análises físicas, químicas, físico-químicas e bioquímicas foram realizadas a cada 3 dias.

Foram analisadas a) acidez titulável: determinada por titulação com solução padronizada de $\mathrm{NaOH} 0,01 \mathrm{~N}$, tendo como indicador a fenolftaleína Os resultados foram expressos em \% de ácido málico; b) teor de sólidos solúveis: determinado por refratometria, utilizando refratômetro digital ATAGO PR-100 e expressos em ${ }^{\circ}$ Brix; c) açúcares solúveis totais: foram extraídos com álcool etílico a $80 \%$ e determinados pelo método de antrona (Dische, 1962). Os resultados foram expressos em g 100 g $\mathrm{g}^{-1}$; d) Poligacturonase (PG): a extração foi realizada segundo a técnica de Buescher \& Fumanski (1978), com modificações de Vilas Boas (1995). O doseamento da PG foi realizado segundo Markovic et al. (1975), com modificações de Vilas Boas (1995). A atividade enzimática foi expressa em nmol de ácido galacturônico $\mathrm{g}^{-1} \mathrm{~min}^{-1}$; e) pectina solúvel: foi extraída de acordo com a técnica de McCready \& McComb (1952) e determinada espectrofotometricamente a $530 \mathrm{~nm}$. f) cor: os valores $\mathrm{L}^{*}, \mathrm{a}^{*} \mathrm{e}$ $b^{*}$ foram medidos, por reflectrometria, utilizando-se colorímetro Minolta, modelo CR 300. Onde a coordenada $\mathrm{L}^{*}$ indica quão claro e quão escuro é o produto (valor zero cor preta e valor 100 cor branca), a coordenada a* está relacionada à intensidade de verde $(-50)$ e vermelho $(+100)$ e a coordenada b* está relacionada à intensidade de azul (-70) e amarelo (+70); g) peroxidase (POD): A extração e determinação da atividade da peroxidase foram realizadas de acordo com o método proposto por Matsumo \& Uritane (1972). A atividade expressa em unidade por minuto por grama de tecido fresco ( $\mathrm{U} \mathrm{min}^{-1} \mathrm{~g}^{-1}$ ), segundo o método de Teisson (1979); h) fenilalanina amônia-liase (PAL): foi realizada com base na técnica preconizada por Rhodes \& Wooltorton (1971). A atividade enzimática foi expressa em $\mathrm{U} \mathrm{min}^{-1}$ $\mathrm{g}^{-1}$, definida como conteúdo de enzima que produz um aumento na absorbância a $290 \mathrm{~nm}$ de 0,01 por minuto (Zucker, 1965); I) polifenoloxidase (PPO): a extração e determinação da atividade da PPO foram realizadas de acordo com o método proposto por Matsumo \& Uritane (1972). A atividade expressa em unidade por minuto por grama de tecido fresco ( $\mathrm{U} \mathrm{min}^{-1} \mathrm{~g}^{-1}$ ), segundo o método de Teisson (1979); j) taxa respiratória: foi determinada utilizando recipientes de vidro os quais foram fechados por 1 hora, com tampa plástica, contendo septo de silicone, por onde foram retiradas alíquotas da atmosfera interna, com auxílio do analisador de gases PBI Dansensor. Os resultados, expressos em $\%$ de $\mathrm{CO}_{2}$, foram convertidos em $\mathrm{mL}$ $\mathrm{CO}_{2} \mathrm{~kg}^{-1} \mathrm{~h}^{-1}$, levando-se em consideração o volume do recipiente, a massa e o volume dos frutos em cada recipiente e o tempo que esse mesmo recipiente permaneceu fechado.

As análises estatísticas foram realizadas com o auxílio do programa SISVAR (Ferreira, 2000). Após a análise de variância, as médias, foram comparadas pelo teste de Tukey a 1 e $5 \%$ de probabilidade. Os modelos de regressões polinomiais foram selecionados com base na significância do teste de F de cada modelo testado e também pelo coeficiente de determinação.

\section{RESULTADOS E DISCUSSÃO}

A acidez titulável e o teor de sólidos solúveis foram influenciados significativamente apenas pelo tempo de armazenamento. Houve um aumento nos teores de acidez titulável a partir do sexto dia, independentemente da temperatura de 


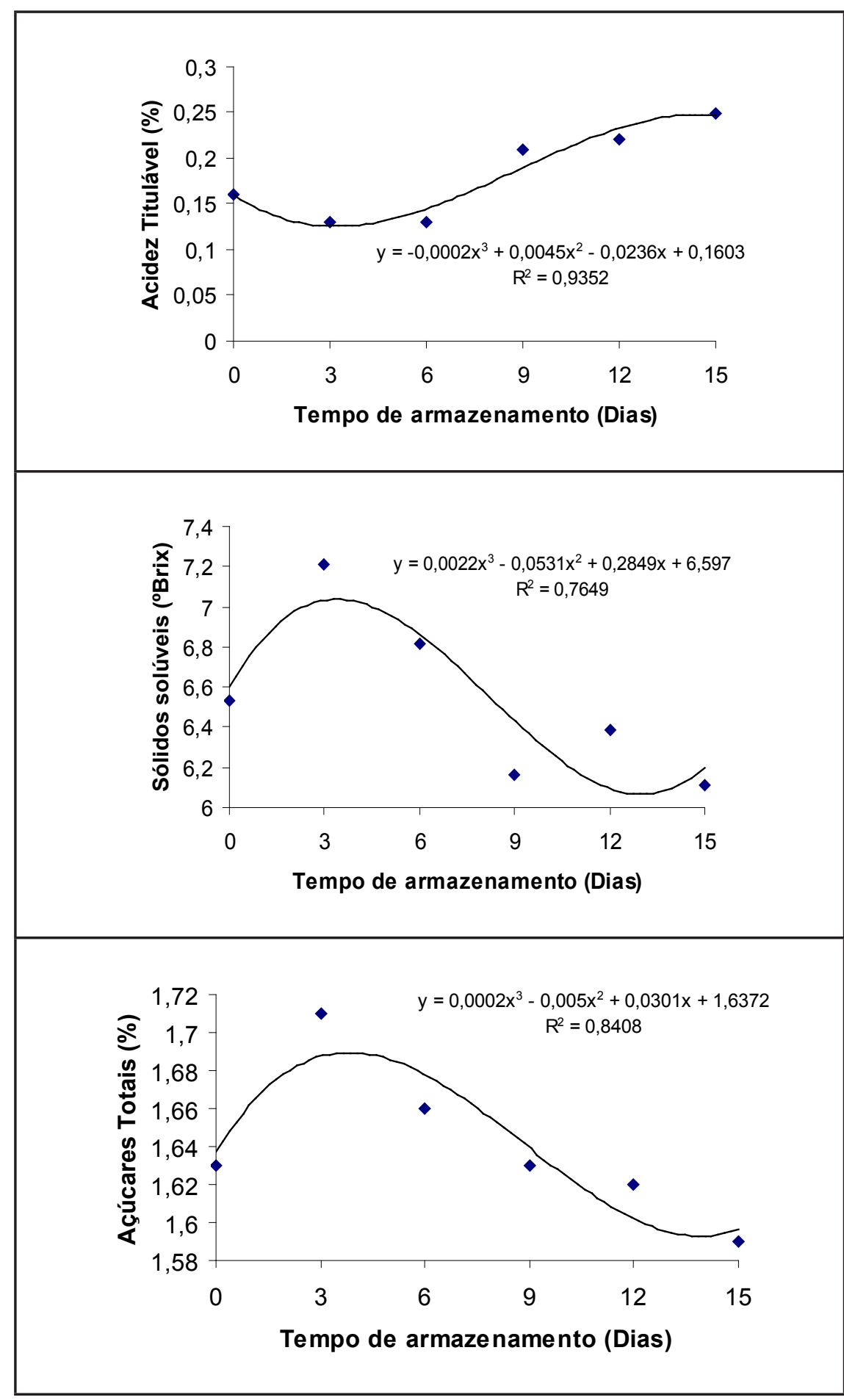

Figura 1. Acidez titulável, sólidos solúveis e açúcares solúveis totais de mandioquinhasalsa minimamente processada armazenada em diferentes temperaturas $\left(0 ; 5 ;\right.$ ou $\left.10^{\circ} \mathrm{C}\right)$ (titratable acidity, soluble solids and total soluble sugars of fresh cut Peruvian carrot stored under different temperatures: 0; 5 or $10^{\circ} \mathrm{C}$ ). Lavras, UFLA, 2007.

armazenamento (Figura 1). Segundo Roura et al. (2000), logo após o processamento mínimo, o tecido vegetal apresenta uma respiração maior, levando a uma diminuição da acidez no início do armazenamento, devido ao consumo dos ácidos orgânicos (substâncias de reser- va) no processo respiratório. $\mathrm{O}$ aumento na acidez de produtos armazenados por curtos períodos de armazenamento pode ser explicado pela geração de radicais (ácidos galacturônicos) a partir da hidrólise dos constituintes da parede celular, em especial, as pectinas (Senter et al., 1991).

Os teores de sólidos solúveis aumentaram até o terceiro dia de armazenamento, declinando em seguida, até o final do armazenamento. $\mathrm{O}$ aumento ocorrido no terceiro dia de armazenamento pode estar relacionado com possíveis reações bioquímicas na parede celular. A redução dos sólidos solúveis pode ter sido influenciada pelo aumento da taxa respiratória do produto, utilizando as reservas existentes nas células (Figura 1).

O teor de açúcares totais foi influenciado significativamente apenas pelo fator de tempo de armazenamento, tendo sido observado declínio ao longo do armazenamento a partir do terceiro dia de armazenamento (Figura 1). Foi observado comportamento semelhante ao teor de sólidos solúveis, uma vez que são carboidratos de baixo peso molecular, componentes dos sólidos solúveis, responsáveis diretos pela determinação do sabor doce de frutos e hortaliças (Santos et al., 2005).

Foi observado efeito interativo dos fatores temperaturas e tempo de armazenamento para as variáveis PG e pectina solúvel. As fatias armazenadas a $0^{\circ} \mathrm{C}$ apresentaram menor atividade da PG e solubilização péctica quando comparadas às fatias armazenadas a 5 e $10^{\circ} \mathrm{C}$ (Tabela 1$)$.

Verificou-se interação significativa entre os fatores tempo de armazenamento e temperatura de armazenamento para os valores $L^{*}, a^{*}$ e $b^{*}$. No sexto dia de armazenamento as fatias armazenadas a $10^{\circ} \mathrm{C}$ apresentavam-se mais escuras que as armazenadas a $0^{\circ} \mathrm{C}$, uma vez que apresentaram os menores valores de $\mathrm{L}^{*}$ e os maiores valores de $\mathrm{a}^{*}$. $\mathrm{O}$ valor $\mathrm{L}^{*}$ é um indicador de escurecimento durante o armazenamento, resultante de reações de escurecimento oxidativo ou aumento da concentração de pigmentos. Segundo Haminiuk et al. (2005), diminuição no valor $\mathrm{L}^{*}$ e aumento no valor de $\mathrm{a}^{*}$ são indicativos de escurecimento. A temperatura de $0^{\circ} \mathrm{C}$ foi efetiva em retardar a redução do valor $b^{*}$ em comparação $a$ 5 e $10^{\circ} \mathrm{C}$, ao longo do armazenamento. Logo, as fatias de mandioquinha-salsa armazenadas a $0^{\circ} \mathrm{C}$ apresentavam coloração mais amarela, o que faz com que sejam mais aceitas pelos consumidores 
Tabela 1. Atividades de poligalacturonase e conteúdo de pectina solúvel de mandioquinhassalsa minimamente processada armazenada em diferentes temperaturas (polygalacturonase activity and content of soluble pectin of fresh cut Peruvian carrot stored under different temperatures). Lavras, UFLA, 2007.

\begin{tabular}{|c|c|c|c|c|c|c|}
\hline \multirow{3}{*}{$\begin{array}{l}\text { Temperatura de } \\
\text { armazenamento }\end{array}$} & \multicolumn{6}{|c|}{ Dias de armazenamento } \\
\hline & $\mathbf{0}$ & 3 & 6 & 9 & 12 & 15 \\
\hline & \multicolumn{6}{|c|}{ Poligalacturonase $\left(\mathrm{nmol} \mathrm{min}^{-1} \mathrm{~g}^{-1}\right)$} \\
\hline $0^{\circ} \mathrm{C}$ & $8,10 \mathrm{a}$ & $8,00 \mathrm{~b}$ & $7,72 \mathrm{~b}$ & $8,00 \mathrm{c}$ & $8,46 \mathrm{c}$ & $8,53 \mathrm{c}$ \\
\hline $5^{\circ} \mathrm{C}$ & $8,15 \mathrm{a}$ & 8,39 a & $8,60 \mathrm{a}$ & $9,02 \mathrm{~b}$ & $8,99 \mathrm{~b}$ & $8,86 \mathrm{~b}$ \\
\hline \multirow[t]{2}{*}{$10^{\circ} \mathrm{C}$} & 8,08 a & 8,33 a & $8,61 \mathrm{a}$ & $9,34 \mathrm{a}$ & $9,28 \mathrm{a}$ & $9,25 \mathrm{a}$ \\
\hline & \multicolumn{6}{|c|}{ Pectina solúvel (\%) } \\
\hline $0^{\circ} \mathrm{C}$ & $155,27 \mathrm{a}$ & $181,30 \mathrm{~b}$ & $192,23 \mathrm{c}$ & $242,67 \mathrm{c}$ & $249,93 \mathrm{c}$ & $253,37 \mathrm{~b}$ \\
\hline $5^{\circ} \mathrm{C}$ & $159,10 \mathrm{a}$ & $206,43 \mathrm{a}$ & $213,33 \mathrm{~b}$ & $268,17 \mathrm{~b}$ & $265,20 \mathrm{~b}$ & $278,10 \mathrm{a}$ \\
\hline $10^{\circ} \mathrm{C}$ & $158,10 \mathrm{a}$ & $200,73 \mathrm{a}$ & $236,03 \mathrm{a}$ & $286,73 \mathrm{a}$ & $291,73 \mathrm{a}$ & $290,60 \mathrm{a}$ \\
\hline
\end{tabular}

Médias seguidas da mesma letra, na coluna, não diferem estatisticamente entre si pelo teste de Tukey $(p \leq 0,05)$ (means followed by the same letter in the column did not differ significantly from each other by Tukey test $(\mathrm{p} \leq 0.05)$.

Tabela 2. Valores de $\mathrm{L}^{*}, \mathrm{a}^{*}, \mathrm{~b}^{*}$ e atividade de peroxidase e fenilalanina amônia-liase de mandioquinhas-salsa minimamente processada armazenads em diferentes temperaturas (values of $\mathrm{L}^{*}, \mathrm{a}^{*}, \mathrm{~b}^{*}$ and activities of peroxidase and phenylalanine ammonia lyase of fresh cut Peruvian carrot stored under different temperatures). Lavras, UFLA, 2007.

\begin{tabular}{|c|c|c|c|c|c|c|}
\hline \multirow{3}{*}{$\begin{array}{l}\text { Temperatura de } \\
\text { armazenamento }\end{array}$} & \multicolumn{6}{|c|}{ Dias de armazenamento } \\
\hline & $\mathbf{0}$ & 3 & 6 & 9 & 12 & 15 \\
\hline & \multicolumn{6}{|c|}{ Valor L* } \\
\hline $0^{\circ} \mathrm{C}$ & $79,88 \mathrm{a}$ & 81,33 a & $80,48 \mathrm{a}$ & 81,23 a & 81,68 a & $80,54 \mathrm{a}$ \\
\hline $5^{\circ} \mathrm{C}$ & 79,88 a & $80,71 \mathrm{a}$ & $80,13 \mathrm{ab}$ & $79,23 \mathrm{~b}$ & $78,50 \mathrm{~b}$ & $77,65 \mathrm{~b}$ \\
\hline \multirow[t]{2}{*}{$10^{\circ} \mathrm{C}$} & 79,88 a & $80,68 \mathrm{a}$ & $78,73 \mathrm{~b}$ & $77,89 \mathrm{~b}$ & $76,69 \mathrm{c}$ & $71,54 \mathrm{c}$ \\
\hline & \multicolumn{6}{|c|}{ Valor a* } \\
\hline $0^{\circ} \mathrm{C}$ & $-1,84 \mathrm{a}$ & $-1,37 \mathrm{a}$ & $-1,13 \mathrm{a}$ & $-0,36 b$ & $0,31 \mathrm{c}$ & $0,58 \mathrm{c}$ \\
\hline $5^{\circ} \mathrm{C}$ & $-1,84 \mathrm{a}$ & $-1,31 \mathrm{a}$ & $-1,16$ a & $-0,34 b$ & $1,01 \mathrm{~b}$ & $2,28 \mathrm{~b}$ \\
\hline \multirow[t]{2}{*}{$10^{\circ} \mathrm{C}$} & $-1,84 a$ & $-1,06 \mathrm{a}$ & $-0,03 \mathrm{~b}$ & $1,93 \mathrm{a}$ & $3,80 \mathrm{a}$ & $4,66 \mathrm{a}$ \\
\hline & \multicolumn{6}{|c|}{ Valor b* } \\
\hline $0^{\circ} \mathrm{C}$ & 42,93 a & $38,50 \mathrm{a}$ & 36,37 a & $35,94 \mathrm{a}$ & 34,88 a & 35,18 a \\
\hline $5^{\circ} \mathrm{C}$ & 42,93 a & $37,19 \mathrm{ab}$ & $33,51 \mathrm{~b}$ & $32,46 \mathrm{~b}$ & $31,94 \mathrm{~b}$ & $32,14 \mathrm{~b}$ \\
\hline \multirow[t]{2}{*}{$10^{\circ} \mathrm{C}$} & $42,93 \mathrm{a}$ & $35,13 \mathrm{~b}$ & $31,77 \mathrm{~b}$ & $31,09 \mathrm{~b}$ & $32,77 \mathrm{~b}$ & $31,49 \mathrm{~b}$ \\
\hline & \multicolumn{6}{|c|}{ Peroxidase $\left(\mathrm{U} \mathrm{min}^{-1} \mathrm{~g}^{-1}\right)$} \\
\hline $0^{\circ} \mathrm{C}$ & $78,35 \mathrm{a}$ & $77,93 \mathrm{c}$ & $97,27 \mathrm{c}$ & $105,34 \mathrm{c}$ & $126,31 \mathrm{c}$ & $129,80 \mathrm{c}$ \\
\hline $5^{\circ} \mathrm{C}$ & 82,47 a & $105,17 \mathrm{~b}$ & $119,41 \mathrm{~b}$ & $157,29 \mathrm{~b}$ & $191,17 \mathrm{~b}$ & $198,76 \mathrm{~b}$ \\
\hline \multirow[t]{2}{*}{$10^{\circ} \mathrm{C}$} & $77,56 \mathrm{a}$ & $139,61 \mathrm{a}$ & $150,34 \mathrm{a}$ & $190,67 \mathrm{a}$ & $205,51 \mathrm{a}$ & $223,45 \mathrm{a}$ \\
\hline & \multicolumn{6}{|c|}{ Fenilalanina amônia-liase $\left(\mathrm{U}\right.$ min$\left.^{-1} \mathrm{~g}^{-1}\right)$} \\
\hline $0^{\circ} \mathrm{C}$ & $1,62 \mathrm{a}$ & $3,77 \mathrm{a}$ & $5,04 \mathrm{a}$ & $7,03 \mathrm{a}$ & $5,57 \mathrm{a}$ & $6,30 \mathrm{a}$ \\
\hline $5^{\circ} \mathrm{C}$ & $1,08 \mathrm{a}$ & $0,91 \mathrm{~b}$ & $0,85 \mathrm{~b}$ & $0,92 \mathrm{~b}$ & $0,83 \mathrm{~b}$ & $0,81 \mathrm{~b}$ \\
\hline $10^{\circ} \mathrm{C}$ & $0,96 \mathrm{a}$ & $0,83 \mathrm{~b}$ & $0,82 \mathrm{~b}$ & $0,71 \mathrm{~b}$ & $0,69 \mathrm{~b}$ & $0,64 \mathrm{~b}$ \\
\hline
\end{tabular}

Médias seguidas da mesma letra, na coluna, não diferem estatisticamente entre si pelo teste de Tukey $(\mathrm{p} \leq 0,05)$ (means followed by same letter in column did not differ significantly from each order by Tukey test $(\mathrm{p} \leq 0.05)$.
(Tabela 2).

A atividade das enzimas POD e PAL foi afetada significativamente pelos fatores temperatura e tempo de armazenamento. A temperatura de $0^{\circ} \mathrm{C}$ foi efetiva em retardar a atividade da POD e da PAL, em comparação às armazenadas a 5 e $10^{\circ} \mathrm{C}$ (Tabela 3 ), o que sugere que na temperatura mais baixa, estas enzimas atuaram formando lignina induzidas pelo frio. A POD participa do escurecimento em hortaliças minimamente processadas e está relacionada com processos de cicatrização juntamente com a PAL como, por exemplo, a lignificação (Cantos et al., 2002). A lignina é um polímero complexo formado a partir de uma mistura de fenilpropanóides simples. Muitos desses compostos são induzidos por diferentes estresses, tais como os danos causados pelo frio. $\mathrm{O}$ ácido clorogênico, os ésteres de alquil ferulato e outros ésteres fenólicos de parede celular podem agir diretamente como componentes de defesa ou podem ser precursores da síntese de lignina, suberina e outras barreiras polifenólicas (Dixon \& Paiva, 1995).

Atividade da PPO foi afetada significativamente pelo tempo de armazenamento e temperatura, isoladamente. Ao longo do armazenamento houve um incremento na atividade da PPO (Figura 3). Na temperatura de $0^{\circ} \mathrm{C}$ foi verificada menor atividade dessa enzima $(51,76 \mathrm{U}$ $\left.\min ^{-1} \mathrm{~g}^{-1}\right)$ quando comparada com o armazenamento a $5^{\circ} \mathrm{C}\left(69,86 \mathrm{U} \mathrm{min}^{-1} \mathrm{~g}^{-1}\right) \mathrm{e}$ $10^{\circ} \mathrm{C}\left(77,06 \mathrm{U} \mathrm{min}^{-1} \mathrm{~g}^{-1}\right)$. O escurecimento enzimático requer quatro diferentes componentes: oxigênio, enzimas, cobre e substrato. A enzima mais importante em frutos e hortaliças minimamente processadas é a PPO. Os fatores que influenciam tal escurecimento em frutos e hortaliças são a concentração da PPO, componentes fenólicos presentes, $\mathrm{pH}$, temperatura e disponibilidade de $\mathrm{O}_{2}$ nos tecidos (Laurila et al., 1998).

A taxa respiratória foi influenciada significativamente pela interação entre os fatores temperatura e tempo de armazenamento. Até o $3^{\circ}$ dia de armazenamento não foi verificada diferença significativa no comportamento respiratório das fatias de mandioquinha-salsa armazenadas a $0 ; 5$ e $10^{\circ} \mathrm{C}$. A partir do $6^{\circ}$ dia, até o final do armazenamento, 


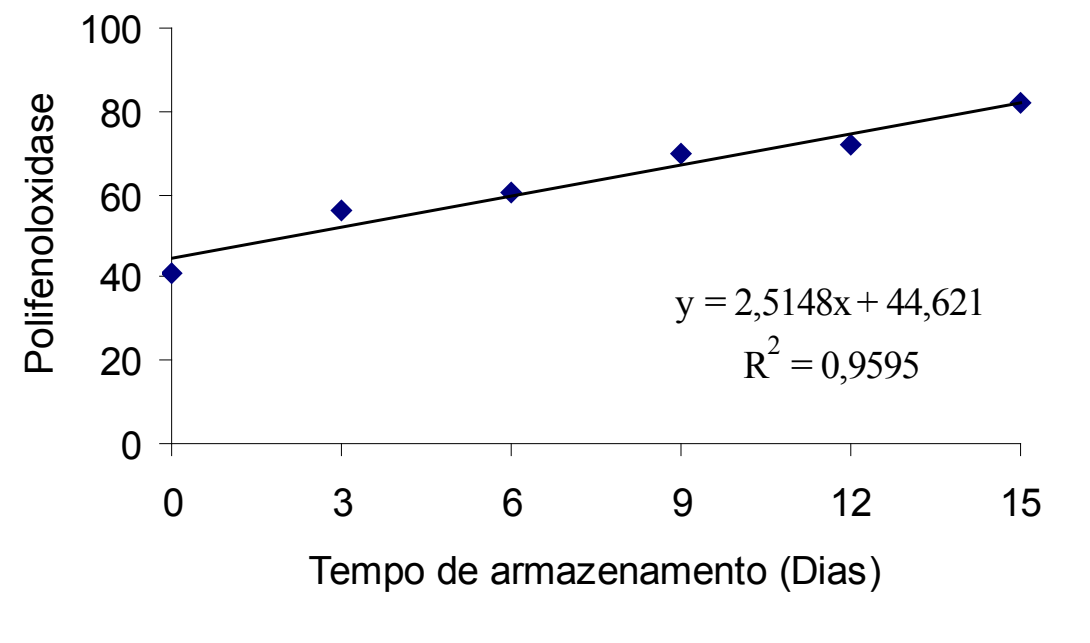

Figura 2. Atividade de polifenoloxidase de mandioquinhas-salsa minimamente processadas armazenadas em diferentes temperaturas $\left(0 ; 5\right.$ ou $\left.10^{\circ} \mathrm{C}\right)$ (polyphenoloxidase activity of fresh cut Peruvian carrot stored under different temperatures: $0 ; 5$ or $\left.10^{\circ} \mathrm{C}\right)$. Lavras, UFLA, 2007.

Tabela 3. Taxa respiratória $\left(\mathrm{mL} \mathrm{CO}_{2} \mathrm{~kg}^{-1} \mathrm{~h}^{-1}\right)$ de mandioquinhas-salsa minimamente processada armazenada em diferentes temperaturas (respiratory rate $\left(\mathrm{mL} \mathrm{CO}_{2} \mathrm{~kg}^{-1} \mathrm{~h}^{-1}\right)$ of fresh cut Peruvian carrot stored under different temperatures). Lavras, UFLA, 2007.

\begin{tabular}{ccrrrrr}
\hline \multirow{2}{*}{$\begin{array}{c}\text { Temperatura de } \\
\text { armazenamento }\end{array}$} & $\mathbf{0}$ & $\mathbf{3}$ & $\mathbf{6}$ & $\mathbf{9}$ & $\mathbf{1 2}$ & $\mathbf{1 5}$ \\
\cline { 2 - 7 } & $7,37 \mathrm{a}$ & $8,93 \mathrm{a}$ & $21,02 \mathrm{a}$ & $19,67 \mathrm{a}$ & $16,33 \mathrm{a}$ & $11,98 \mathrm{a}$ \\
$0^{\circ} \mathrm{C}$ & $8,68 \mathrm{a}$ & $9,90 \mathrm{a}$ & $28,75 \mathrm{~b}$ & $34,55 \mathrm{~b}$ & $28,90 \mathrm{~b}$ & $16,15 \mathrm{~b}$ \\
$5^{\circ} \mathrm{C}$ & $8,48 \mathrm{a}$ & $10,27 \mathrm{a}$ & $44,25 \mathrm{c}$ & $34,63 \mathrm{~b}$ & $30,15 \mathrm{~b}$ & $16,76 \mathrm{~b}$ \\
$10^{\circ} \mathrm{C}$ &
\end{tabular}

Médias seguidas da mesma letra, na coluna, não diferem estatisticamente entre si pelo teste de Tukey $(p \leq 0,05)$ (means followed by same letter in column did not differ significantly from each order by Tukey test $(\mathrm{p} \leq 0.05))$.

as fatias armazenadas à temperatura de $0^{\circ} \mathrm{C}$ apresentaram menores valores de taxa respiratória do que as armazenadas a 5 e $10^{\circ} \mathrm{C}$ (Tabela 4). A temperatura é um dos fatores de maior influência na respiração, havendo um valor ideal para a manutenção de cada tipo de produto vegetal, para que esse alcance um máximo de qualidade comestível. A atividade respiratória é reduzida pelo uso de baixas temperaturas (Chitarra \& Chitarra, 2005). Assim, conclui-se que a mandioquinha-salsa 'Amarela de Senador Amaral' minimamente processada, quando armazenada $0^{\circ} \mathrm{C}$, preserva a qualidade, mantendo maiores valores de $\mathrm{L}^{*} \mathrm{e} \mathrm{b}^{*}$, menores valores de $\mathrm{a}^{*}$, menor atividade da peroxidase, polifenoloxidase, poligalacturonase, solubilização péctica e taxa respiratória, sendo esta a temperatura ideal para armazenamento e conservação do produto.

\section{AGRADECIMENTOS}

Os autores agradecem ao CNPq, a CAPES e a FAPEMIG pelo apoio financeiro.

\section{REFERÊNCIAS}

AVELAR FILHO JA. 1989. Estudo da conservação pós-colheita da mandioquinhasalsa (Arracacia xanthorrhiza Bancroft). Viçosa: UFV. 42p. (Tese mestrado).

BRECHT JK. 1995. Physiology of lightly processed fruits and vegetables. Hortscience 30: $18-22$.

BUESCHER RW; FURMANSKI RJ. 1978. Role of pectinesterase and polygalacturonase in the formation of woolliness in peaches. Journal of Food Science 43: 264-266.

CANTOS E; TUDELA JA; GIL MI; ESPÍN JC. 2002. Phenolic compounds and related enzymes are not rate-limiting in browning development of fresh-cut potatoes. Journal of Agricultural and Food Chemistry 50: 3015-3023.

CHITARRA MIF; CHITARRA AB. 2005. Póscolheita de frutos e hortaliças: fisiologia e manuseio. 2.ed. Lavras: UFLA, 785p.
DISCHE Z. 1962. General color reactions. In: WHISTLER RL; WOLFRAM ML. (ed). Carbohydrate chemistry. New York: Academic, p.477-512.

DIXON RA; PAIVA NL. 1995. Stress-induced phenylpropanoid metabolism. Plant Cell 7:1085-1097.

FERREIRA DF. 2000. Análises estatísticas por meio do SISVAR para windows versão 4.0. In: REUNIÃO ANUAL DA REGIÃO BRASILEIRA DA SOCIEDADE INTERNACIONAL DE BIOMETRIA, Resumos... São Carlos, SP: UFSCar, p.235.

HAMINIUK CWI; OLIVEIRA CRG; BAGGIO ECR; MASSON ML. 2005. Efeito de prétratamentos no escurecimento das cultivares de maçã Fuji e Gala após o congelamento. Ciência e Agrotecnologia 29: 1029-1033.

LANA MM; NASCIMENTO EF; MELO MF. 1998. Manipulação e comercialização de hortaliças. Brasília: Embrapa-SPI/Embrapa $\mathrm{CNPH}, 47 \mathrm{p}$.

LAURILA E; KERVINEN R; AHVENAINEN R. 1998. The inhibition of enzymatic browning in minimally processed vegetables and fruits. Postharvest News and Information 9:53-65.

McCREADYPM; McCOMB EA. 1952. Extraction and determination of total pectic material. Analytical Chemistry 1586-1588.

MADEIRANR; SOUZARJ. 2004. Mandioquinhasalsa: alternativa para o pequeno produtor. Lavras: UFLA. (UFLA. Boletim Agropecuário da Universidade Federal de Lavras, 60).

MARKOVIC O; HEINRICHOVÁ K; LENKEY B. 1975. Pectolytic enzymes from banana. Collection Czechoslovak Chemistry Community, 40: 769-774.

MATSUMO H; URITANI I. 1972. Phisiological behavior of peroxidase enzimas in sweet potato root tissue injured by cutting or back root. Plant and Cell Physiology 13: 1091-1101.

PEREIRA AS. 1997. Valor nutritivo da mandioquinha-salsa. Informe Agropecuário 19: 11-12.

RINALDI MM; BENEDETTI BC; CALORE L. 2005. Efeito da embalagem e temperatura de armazenamento em repolho minimamente processado. Ciência e Tecnologia de Alimentos 25: 480-486.

ROURA SI; DAVIDOVICH LA; DEL VALLE CE. 2000. Quality loss in minimally processed swiss related to amount of damage area. Lebensmittel Wissenschaft und Technology 23: 53-59.

RHODES MJC; WOOLTORTON LSC. 1971. Changes in the activity of enzymes of phenylpropanoid metabolism in tomatoes stored at low temperatures. Phytochemistry 16: 655-659.

SANTOS JCB; VILAS BOAS EVB; PRADO MET; PINHEIRO ACM. 2005. Avaliação da qualidade do abacaxi 'Pérola' minimamente processado armazenado sob atmosfera modificada. Ciência e Agrotecnologia. 29: 346-352.

SENTER SD; CHAPMAN GW; FORBUS WR; PAYNE JA. 1991. Sugar and non-volatile acid composition of persimmons during maturation. Journal of Food Science 56: 980-991.

TEISSON C. 1979. Lê brunissement interne de I'ananás. I-Historique. II- Material e méthodos. Fruits 34: 245-281.

VILAS BOAS EVB. 1995. Modificações póscolheita de banana 'Prata' (Musa acuminata $x$ Musa balsiniana grupo AAB) Y-irradiada. Lavras: UFLA 73p. (Tese mestrado).

ZUCKER M. 1965. Induction of phenylalanine dreaminase by light and its relation to chlorogenic acid syntesis in potato tuber tissue. Plant Physiology 40: 779-784. 